\title{
A REDE SOCIAL E O HIPERTEXTO COMO ARTEFATOS DE INOVAÇÃO PARA UMA APRENDIZAGEM COLABORATIVA
}

\author{
SOCIAL NETWORK ING AND HYPERTEXT AS ARTIFACTS OF \\ INNOVATION FOR COLLABORATIVE LEARNING
}

\author{
Rosangela Fernandes Sant'Anna \\ Universidade Estácio de Sá - Licenciatura em Teatro \\ ORCID: https://orcid.org/0000-0003-3160-5259 \\ Data de submissão: 04/03/2019 \\ Data de aprovação:19/04/2019
}

\section{RESUMO}

Este artigo apresenta duas sequências didáticas, usando a mídia social Facebook e o ambiente digital Hipertexto e mostra que a inovação não necessariamente é algo novo, mas sim algo que está sendo experimentado em um ambiente construído e se revela como um artefato simples, mas de grande influência no ensino aprendizado. Demonstra neste contexto a importância da colaboração, da interação e apresenta os prós e os contras dessa proposta educacional, passando pela questão de ética e privacidade, que deve sempre estar presente a cada acesso do participante. A partir de um experimento com voluntários com bagagens emocionais, experiências e graus de escolaridade diversificados, originou-se uma turma para estudo online através de um grupo de Facebook e Hipertexto, objetivando uma avaliação qualitativa. Nesse processo, é exposto o método e o arrolamento das atividades, finalizando com propostas de avaliação e uma visão geral do processo.

Palavras-chave: Mídias Sociais. Hipertexto. Ensino. Aprendizagem. Interatividade.

\section{ABSTRACT}

This article presents two didactic sequences using a social media Facebook and the digital environment Hypertext and shows that innovation is not something new, but something that is being experimented in a built environment and reveals itself as a simple artifact, but of great influence not learning. In this context, the importance of collaboration, interaction between students and people has an educational participation, ethics and privacy, which must always be present at each participant's access. From an experiment with emotional exercises, experiences and diversified degrees of schooling, a group was born for the study online through a Facebook group and hypertext, aiming a qualitative evaluation. This process is exposed to the method and the organization of activities, ending with evaluation evaluations and an overview of the process.

Keywords: Social Media. Hypertext. Teaching. Learning. Interactivity. 


\section{INTRODUÇÃO}

Trazemos, neste artigo, a questão da inovação em educação, utilizando-se dois artefatos tecnológicos, o Facebook e o Hipertexto. O tema inovação foi tratado por Cristina Lemos (1999), no final do século passado, que afirmou ser a inovação um processo que se desenvolve como algo novo em um contexto, embora seja amplamente conhecido em outros contextos.

O problema que foi investigado traz as seguintes variáveis: as mídias sociais, os ambientes digitais e o aprendizado na educação formal e na educação não formal.

Nas sequências didáticas utilizadas, testou-se a mídia social Facebook e a tecnologia Hipertexto, de natureza digital. As sequências foram vivenciadas pelos participantes em fases, descritas neste artigo, na metodologia.

A justificativa que moveu o espirito desta experiência é que a comunicação online criou inúmeras formas de interação com mais recursos a cada dia, rompendo barreiras, aproximando, dinamizando e transformando o modo de interagir, pesquisar, aprender e ensinar, abrindo as portas da mente para a introdução de novos comportamentos no trabalho, quebrando barreiras de resistências, pela facilidade de navegação e interação.

No ensino formal, o grande entrave está no fato de as redes sociais serem consideradas, nas instituições de ensino, como um elemento de dispersão. Em muitas situações, o acesso é bloqueado ou limitado para os alunos.

Para a Geração Z, os nativos digitais, é inviável a vida cotidiana sem o uso principalmente do celular e esses já perceberam que a interatividade é uma poderosa aliada no ensino/aprendizagem e que a rede social não é apenas uma ferramenta usada para o lazer.

Neste artigo, apontamos o Facebook e o Hipertexto como parceiros na educação. São recursos ainda em expansão, mas que hoje já fazem parte da cultura dos povos.

O Facebook, criado em 4 de fevereiro de 2004 por Mark Zuckerberg, Dustin Moskovitz e Chris Hughes, alunos da Universidade de Harvard, é uma rede social que desde o início tem o objetivo de configurar um espaço no qual as pessoas possam encontrar umas às outras, dividindo opiniões e fotografias.

A diferença é que, no começo, a rede virtual era limitada ao corpo estudantil da Universidade de Harvard; aos poucos, porém, ela foi estendida ao Instituto de Tecnologia de Massachusetts, à Universidade de Boston, ao Boston College, incluindo também alunos de Stanford, Columbia e Yale1. E hoje espalhou-se pelo mundo inteiro, tornando-se um recurso valioso, um meio imprescindível à educação.

A inclusão digital no Brasil, ainda limitada, impede o avanço educacional para o uso de novas tecnologias, em que a conectividade ainda tem custo alto e acesso escasso. Outra problemática são as implicações no que diz respeito à ética e à privacidade durante o acesso, pois a internet traz benefícios e ao mesmo tempo muitos perigos.

Porém, o aprendizado de forma coletiva e não formal é um enorme atrativo para o aluno que se sente integrado à turma e aos professores, num ambiente virtual que ele ajudará a construir. O professor, assim, passa de "o detentor absoluto do saber" para um mediador, e o aluno, antes passivo, recebedor, passa a ser um pesquisador. 
Os professores têm que repensar o seu papel. Se é certo que continuam a ser fontes de informação, deverão se consciencializar de que são apenas uma fonte de informação, entre muitas outras. É necessário, no entanto, salientar que o seu valor informativo tem níveis diferentes conforme o acesso que os seus alunos puderem ter a outras fontes de informação. É fundamental que os professores percebam esta diversidade. Haverá alunos que não vão precisar muito da informação substantiva dos professores, embora precisem da informação processual no sentido de a digerirem e criticarem (ALARCÃO, 2003, p. 31)

A proposta de ensino utilizando uma rede social com o Hipertexto gera desafios para alunos e educadores por se tratar de uma nova forma de aprendizado na qual ambos estão aprendendo e adaptando-se.

\section{REFERENCIAL TEÓRICO}

\subsection{A educação no contexto não formal e formaL}

A Educação não acontece apenas nas salas de aula dos contextos formais; ao contrário, sua ampla enraização está na cultura e dá-se em contextos informais, no clube, na igreja, nos templos, nas redes sociais, nas mídias sociais, na convivência, na imitação, na cópia das atitudes e comportamentos do outro, na colaboração.

Há uma antropologia no aprendizado, que coloca a educação em foco em seus aspectos formais e informais, pois a mente é social, e aprendemos uns com os outros, seja em sala de aula, seja nas mídias e redes sociais.

Neste artigo, trazemos a mídia social Facebook e o ambiente digital Hipertexto como instrumentos tecnológicos importantes na educação formal e informal, recursos simples ao alcance de todos hoje, inclusive pelo celular, tornando a educação e a transmissão de conteúdos e cultura um fenômeno ubíquo, que é considerado como opção na formação educacional, ética e moral do aluno, sempre vulnerável e apto antropologicamente a aprender.

\subsubsection{O Facebook: Uma mídia para o aprendizado colaborativo}

Segundo o Instituto Brasileiro de Geografia e Estatística (IBGE), o acesso ativo à internet se dá cada vez mais cedo. A partir de 10 anos, o brasileiro se torna um internauta ou usuário ativo.

Figura 1 - Amostra de usuários ativos na internet

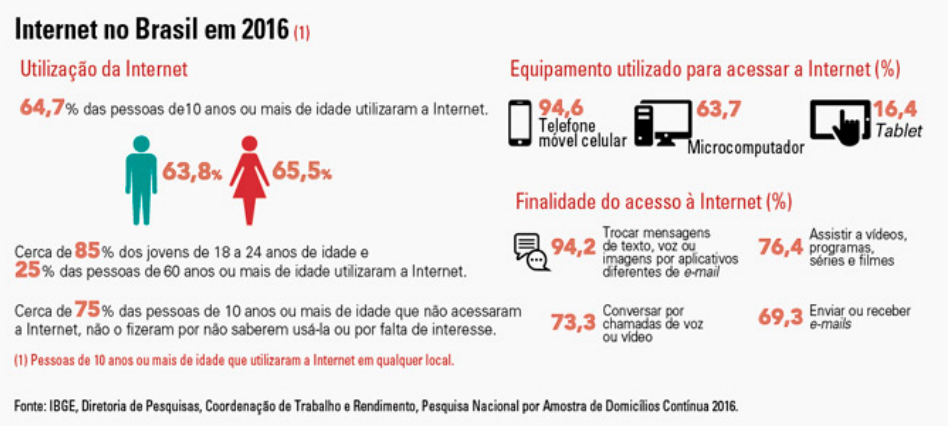

Fonte: IBGE (2018). 
Estes dados confirmam que deve haver alguma mudança nas metodologias de ensino do ensino formal no que se refere à utilização do telefone móvel celular nas rotinas de aprendizagem, pois $85 \%$ das pessoas de 10 anos ou mais de idade utilizaram a internet. Por outro lado, quanto aos equipamentos utilizados para acessar a Internet, $94,6 \%$ o fizeram através de telefone móvel celular. E, como se pode ver abaixo, o Facebook é um recurso valioso de aprendizado a ser utilizado.

O armazenamento, recursos e a colaboração no Facebook possuem integração, não só entre o grupo (alunos), mas também com outros grupos, denotando um intercâmbio cultural. É evidente que a popularização do aplicativo torna relevante a indicação metodológica do Facebook em sala de aula, pois o aluno, familiarizado com a ferramenta, pode utilizá-la dentro de uma proposta educacional de uma forma coordenada.

Portanto, ao usar o "grupo do Face" como uma sala online de aula, levamos o ensino a um patamar mundial, tornando-o uma grande plataforma de intercâmbio cultural, favorecendo a interculturalidade por conta da diversidade cultural de seus usuários e a integração social, que resulta em diferentes culturas trabalhando em uníssono, possibilitando o enriquecimento cultural a todos. O Facebook lidera o ranking com maior número de usuários ativos, pois, além de proporcionar encontros sociais entre pessoas, é hoje em dia também um grande centro comercial, onde é possível comprar e vender produtos e serviços, além de divulgar informações.

Tabela 1 - Ranking das maiores redes sociais

\begin{tabular}{ll}
\multicolumn{1}{c|}{ Rede social } & \multicolumn{1}{c|}{ Usuários ativos } \\
\hline \#1 Facebook & 2.234 .000 .000 \\
\hline \#2 Youtube & $1.900 .000 .000(+400)$ \\
\hline \#3 WhatsApp & 1.500 .000 .000 \\
\hline \#4 Facebook Messenger & 1.300 .000 .000 \\
\hline \#5 Wechat +1 & $1.058 .000 .000(+88)$ \\
\hline \#6 Instagram -1 & 1.000 .000 .000 \\
\hline Fonte: Oficina da Net (2019) &
\end{tabular}

Ao observar-se a tabela acima, nota-se que será um desperdício não usar o Facebook e o Hipertexto como ferramentas de ensino e aprendizado. $O$ nível de interação é altíssimo, o que confirma os aspectos colaborativos da mídia e sua natureza de viabilizar a construção da informação.

\subsubsection{A natureza do digital hipertexto}

Neste trabalho, queremos mostrar que o Facebook é uma mídia social que se alia à ferramenta Hipertexto, que possui natureza digital, produzindo vantagens pedagógicas, tais como: aprendizagem colaborativa, aumento da cognição devido ao salto não linear produzido pelo hipertexto e interação entre vários cenários conectados e abertos pelo hipertexto.

O facebook e o Hipertexto são ferramentas compartilhadas que ajudam na construção conjunta de informações, evidenciando a natureza colaborativa da mente para o aprendizado participativo.

É o que também afirma Monteiro (2015). 
O Hipertexto é uma ferramenta de narrativa e linguagem digitais que interliga em uma mesma rede diferentes blocos de conteúdo (texto, imagens, vídeos, áudios e infográficos), que se vinculam a outros, mantendo uma relação de elo associativo entre si e que podem ser acessados através de links. A velocidade e a estrutura hipertextual ultrapassam, tanto em quantidade como em qualidade, a recepção da informação transmitida de forma oral.

\title{
2.1.3 Privacidade e ética
}

Ao se usar o facebook com Hipertexto na metodologia de aulas, as questões de privacidade e ética devem ser bem definidas, deixando claro ao aluno que há normas no que se refere à conduta de educação e respeito com os colegas. Essa ação deve ser feita antes mesmo da implementação do grupo de estudos online. A exposição desnecessária e o compartilhamento de conteúdo pessoal são reprimidos (deletados) ou publicados após aprovação anterior do professor administrador. E vale ressaltar que há os cuidados básicos que todos devem ter com a segurança online e que, às vezes, deixamos de lado, como antivírus, firewall e atualizações. Conclui-se que independente do conteúdo que será ministrado, o docente deve passar essas questões antecipadamente ao seu aluno.

Com o aumento da acessibilidade, também crescem os registros de crimes cibernéticos. De acordo com pesquisa da empresa de cibersegurança Symantec, mais de 62 milhões de pessoas, no Brasil, foram afetadas por crimes virtuais, somente em 2017; em 2016, esse número era de 42,4 milhões.

\section{METODOLOGIA}

A Metodologia adotada pressupôs uma pesquisa qualitativa, de caráter teórico, e definiu-se como um experimento, pois no método de pesquisa experimental, o aluno assume o papel de pesquisador, torna-se totalmente ativo e se envolve com o tema que está estudando. Ele manipula as variáveis do contexto em estudo: mídia social, ambiente digital e aprendizado e controla o objeto de estudo, ou seja, a mídia social e ambiente digital.

A partir deste modelo metodológico, foi criada uma página no Facebook para o desenvolvimento dos trabalhos, cuja configuração baseou-se nas seguintes informações de conteúdo da página:

\author{
Elaboração de atividades. \\ Bate papo em grupo (dia e hora marcada) \\ Enquetes \\ Publicações de fotos e/ou documentos \\ Comunicações de eventos \\ Transmissão de vídeo ao vivo (dia e hora marcada) \\ Envio de lembretes
}

Com o ambiente da página do grupo pronto, fez-se a inserção dos alunos. Deste ponto em diante, já pode ser observado através de comentários dos alunos o seu grau de participação e comprometimento. 
A Rede Social e o Hipertexto como Artefatos de Inovação para uma Aprendizagem Colaborativa

Quadro 1 - Dados da pesquisa

\begin{tabular}{|c|l|l|l|}
\hline $\begin{array}{c}\text { Alunos } \\
\text { voluntários }\end{array}$ & \multicolumn{1}{|c|}{ Idade } & \multicolumn{1}{|c|}{ Profissão } & Naturalidade \\
\hline Integrante 1 & 50 anos & Professora de balé & Rio de Janeiro \\
\hline Integrante 2 & 21 anos & Estudante de Letras & Rio de Janeiro \\
\hline Integrante 3 & 70 anos & Empresário & Minas Gerais \\
\hline Integrante 4 & 30 anos & Ator profissional & Curitiba \\
\hline Integrante 5 & 22 anos & Estudante de Marketing & Goiás \\
\hline Integrante 6 & 49 anos & Musico & Rio de Janeiro \\
\hline Integrante 7 & 52 anos & Professora de História & Rio de Janeiro \\
\hline Integrante 8 & 28 anos & Professora de Artes & Ceará \\
\hline Integrante 9 & 30 anos & Engenheiro & Rio de Janeiro \\
\hline Integrante 10 & 49 anos & Produtora de Eventos & Rio de Janeiro \\
\hline
\end{tabular}

Fonte: Elaborada pelo autor (2019)

Foi definido que somente o "administrador professor" poderia adicionar ou excluir os integrantes. Foi inserida na página a foto de destaque, uma descrição resumida da matéria e uma explicação sucinta do objetivo da página e o que se espera de seus integrantes.

No ícone criar regras foi explicada a conduta que se almejava do aluno. As regras foram as seguintes:
1. Seja simpático e gentil;
2. Nenhum discurso de ódio ou bullying será permitido;
3. Nenhuma promoção ou spam;
4. Respeito à privacidade de todos.

\subsection{Método}

Foram usadas duas sequências didáticas:

$\mathrm{Na}$ Sequência 01 (Chegada da Família Real no Brasil), os alunos foram estimulados a pesquisar, interagir entre si, para construírem a informação de forma colaborativa e produzirem um conhecimento coletivo. Na sequência 02, foram levados em conta os processos iterativos de reflexão sobre o que se aprendeu, com o aluno conjeturando sobre o seu próprio aprendizado. A criação de novos conhecimentos surge a partir deste momento, que é silencioso, cronologicamente individual, no qual o aluno, com a sua bagagem pessoal, vivencia um momento de crítica e reflexão sobre seu aprendizado.

\subsubsection{Dados preliminares de campo e análise dos resultados}

Fase 01 - Sequência didática sobre a chegada da família real no brasil - interação e pesquisa

As ilustrações a seguir mostram as atividades aplicadas na página intitulada: A Chegada da Família Real no Brasil - Grupo fechado - Plataforma Facebook (www. facebook.com/groups - Chegada da família Real no Brasil) 
Figura 1 - Chegada da Família Real à Bahia, de Candido Portinari

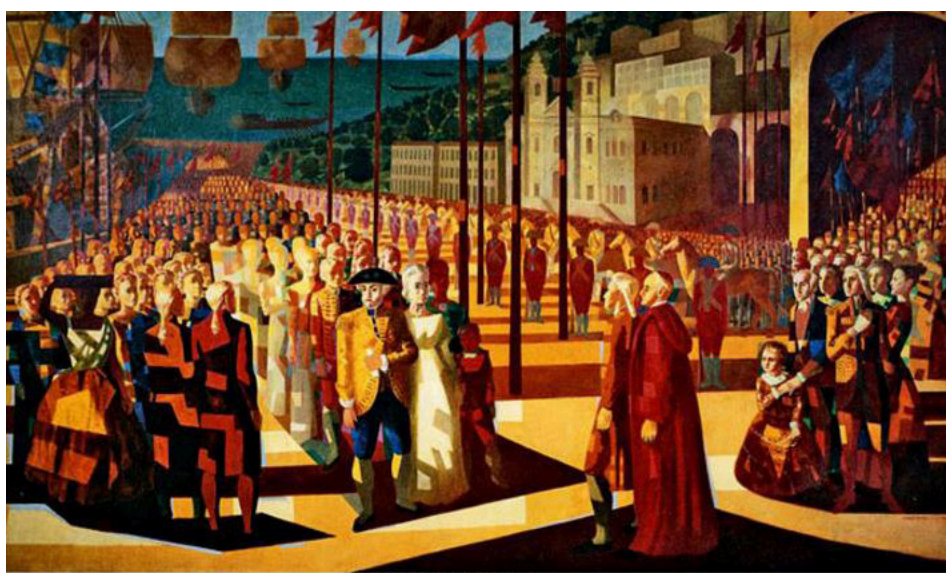

Fonte: Facebook groups - Chegada da Família real no Brasil (2018)

Os alunos trouxeram informações, em seus comentários, sobre a obra, que se trata de uma encomenda feita polo Banco da Bahia, em 1952; há também comentários sobre o enfileiramento perfeito das pessoas e as cores fortes.

Figura 2 - Link do filme Carlota Joaquina, no YouTube

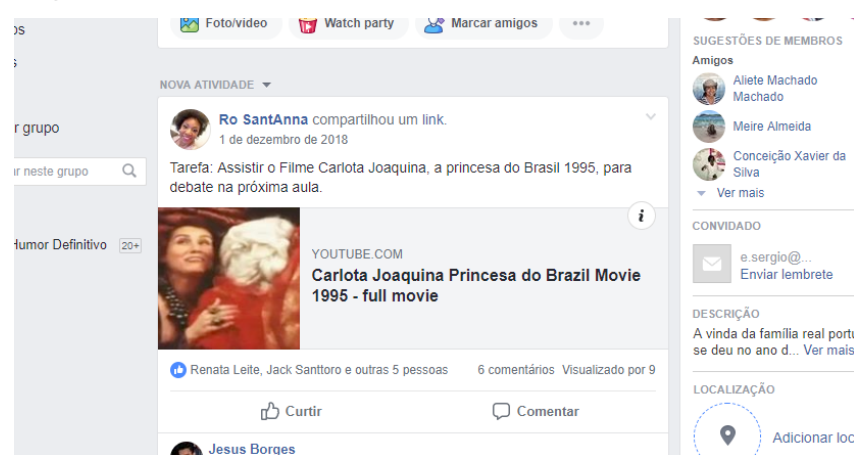

Fonte: Facebook groups - Chegada da Família real no Brasil (2018)

Eles gostaram muito de assistir ao filme. Houve elogios à obra, que mostra, de forma não convencional, a chegada da família real pela visão de Carlota Joaquina. Debateram também de que forma os escândalos eram abafados, através de patentes e cargos.

Figura 3 - Notícias da atualidade, com a finalidade promover um debate, mediado pelo professor

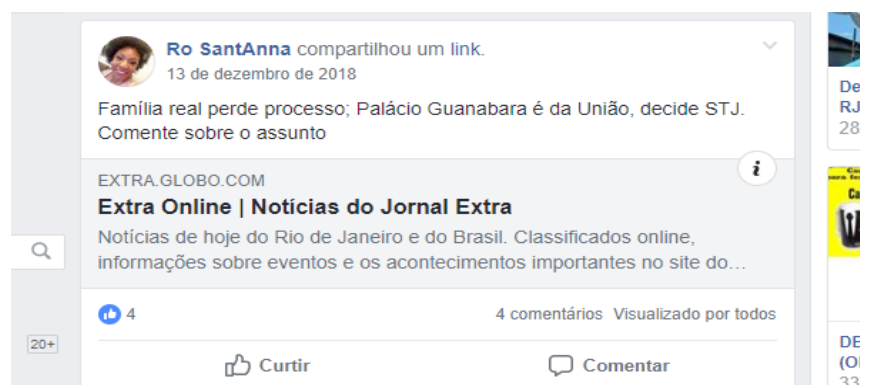

Fonte: Facebook groups - Chegada da Família real no Brasil (2018) 
A partir dessa matéria de jornal (de 2018) que informa que os herdeiros da Família Real perderam o processo que moviam, requerendo a posse do Palácio Guanabara, houve debate sobre o tema, ocasião em que todos os alunos foram contra a reinvindicação e externaram suas opiniões por meio de argumentos e deslikes.

Figura 4-Álbum de fotos da Família Real. Expor personagens e a estética da época.

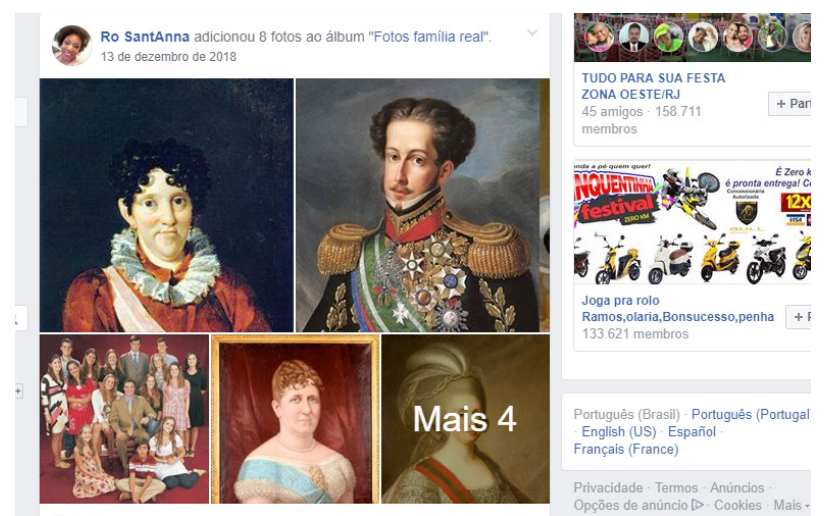

Fonte: Facebook groups - Chegada da Família real no Brasil (2018)

As imagens acima denotam a atenção ao vestuário. Os comentários foram feitos principalmente sobre a imagem física das pessoas da época e suas indumentárias, que eram totalmente inadequadas para o clima tropical.

Figura 5 - Agenda cultural, aberta a contribuições

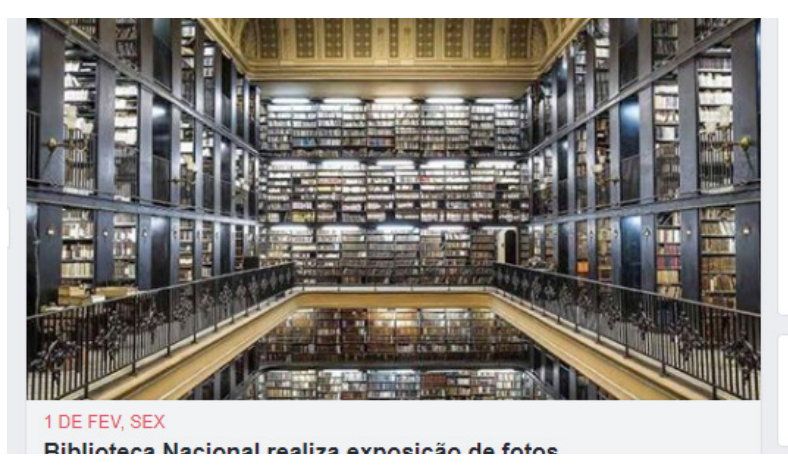

Fonte: Facebook groups - Chegada da Família real no Brasil (2018)

Aqui se vê a agenda cultural que foi desenvolvida com os participantes e que é atualizada com eventos culturais ligados ao tema da chegada da Família Real no Brasil.

Figura 6 - Um "Quiz" educacional

Quais destas não foram benfeitorias feitas após a chegada da família real no brasil?

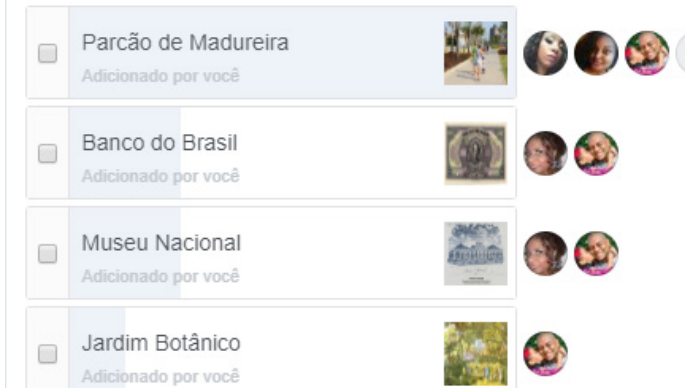

Fonte: Facebook groups - Chegada da Família real no Brasil (2018) 
A partir de uma pergunta de múltipla escolha, foi testado o conhecimento das benfeitorias realizadas pela Família Real no Brasil. Alguns alunos desconheciam várias benfeitorias.

\begin{abstract}
Uma das tarefas mais importantes da prática educativa-crítica é propiciar as condições em que os educandos em suas relações uns com os outros e todos com o professor ou a professora ensaiam a experiência profunda de assumir-se. Assumir-se como ser social e histórico, como ser pensante, comunicante, transformador, criador, realizador de sonhos, capaz de ter raiva porque capaz de amar. (FREIRE, 2000, p. 46)
\end{abstract}

Fase 2 - Sequência didática criada pelos alunos - processos iterativos de reflexão sobre o aprendido e criação de um novo conhecimento

Avançando no ensino e com o intuito de medir o comprometimento e entendimento do conteúdo pedagógico, foi solicitado ao grupo que livremente contribuísse, propondo atividades. Nesse ponto o professor é o mediador e o aluno é o condutor do saber.

A reflexão sobre o que aprendeu mostra-se na proposta de trabalho de cada aluno, observando-se também sua bagagem, que cresce e se desenvolve não só nas mídias e no ambiente digital, mas como uma pessoa integral, com sua narrativa pessoal.

Tabela 1 - Atividades propostas pelos alunos - ordem de postagens ordem de postagens

\begin{tabular}{|c|c|c|}
\hline NOME & IDADE & ATIVIDADE \\
\hline Integrante 1 & 50 anos & $\begin{array}{l}\text { Um sarau com trajes a caráter, músicas e poesia de } \\
\text { autores da época. }\end{array}$ \\
\hline Integrante 2 & 22 anos & $\begin{array}{l}\text { Contribuir na atividade sugerida por Claudia, ficando } \\
\text { responsável por algum setor. }\end{array}$ \\
\hline Integrante 3 & 70 anos & 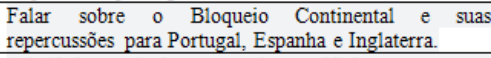 \\
\hline Integrante 4 & 49 anos & $\begin{array}{l}\text { Atividades voltadas ao turismo. Visita aos marcos } \\
\text { imperiais na Zona Oeste (Bangu, Santíssimo e Santa } \\
\text { Cruz) e a Petrópolis. }\end{array}$ \\
\hline Integrante 5 & 30 anos & Participar das atividades de outros alunos. \\
\hline Integrante 6 & 52 anos & $\begin{array}{l}\text { Discussão sobre o "empoderamento" feminino que já } \\
\text { existia na época de forma camuflada, usando como } \\
\text { base a novela Novo Mundo (Rede Globo, 2017) }\end{array}$ \\
\hline Integrante 7 & 21 anos & $\begin{array}{l}\text { Discutir os assuntos sugeridos em uma roda de ideias: } \\
\text { confrontando o passado com a atualidade }\end{array}$ \\
\hline Integrante 8 & 28 anos & Proposta de um jogo de perguntas e respostas. \\
\hline
\end{tabular}

Fonte: o autor (2018).

A partir das propostas, as sequências didáticas foram desenvolvidas, com interação, debates, revelando o conhecimento da turma e sua participação e interação.

É muito importante, neste artigo, registrar que ferramentas como essas estão disponíveis em salas ou no celular e podem ser utilizadas a favor de uma educação mais moderna, que permita aproveitar as qualidades do Facebook de interação, debate, comunicação, socialização. Por outro lado, o Hipertexto é um ambiente digital conectado com o Facebook, oferecendo amplo espectro de colaboração com outros ambientes, permitindo um ensino aprendizado que vai além dos muros da escola, da casa ou de outros espaços em que se esteja interagindo com outras pessoas.

\title{
4 ANÁLISE E DISCUSSÃO DOS RESULTADOS
}

O aluno recebeu, através de mensagem de texto (Messenger), um questionário em que se pode avaliar o desenvolvimento do trabalho. O docente pôde, assim, obter, 
para sua apreciação, uma visão individual e particular de cada integrante da turma. As perguntas e respostas foram as seguintes:

Como foi para você aprender através de uma rede social?

"Os alunos, em sua maioria, se sentiram à vontade de participar e todos afirmaram que usar o Facebook com o Hipertexto permitiu aprender. O ponto alto da experiência foi o fato de várias pessoas interagirem ao mesmo tempo".

Qual atividade foi mais significativa?

"Todos gostaram das atividades que proporcionavam debate e troca de experiências".

Qual atividade não foi significativa?

"Não houve nenhum questionamento sobre a forma como foi usado Facebook nas sequências didáticas desenvolvidas e todos gostaram da forma colaborativa, interativa e hipertextual como foram experienciadas as atividades".

\section{Uma sugestão ou crítica.}

"Antes do início dos trabalhos, deve haver uma apresentação em vídeo dos integrantes e mais material com animações e vídeos durante as aulas".

"Seria muito bom um chat ou bate-papo com dia e hora marcados, em tempo real, para avaliar a experiência e o entendimento do conteúdo aplicado. No debate, o aluno tem a chance de trocar experiências, expor seu ponto de vista e tirar dúvidas. A personalidade de cada um é evidenciada na forma de se expressar neutra ou eloquente, e o professor pode orientar, o que requer em alguns momentos uma percepção do professor como mediador".

"Houve maior socialização e intimidade que em um modelo presencial, que levaria um tempo maior para seu desenvolvimento".

"Essa troca de experiência levou a questionamentos e posteriores debates que foram bem positivos".

\section{CONSIDERAÇÕES FINAIS}

Foram alcançados os objetivos centrais desta proposta educacional: expandir a comunicação, proporcionar um aprendizado diferenciado, utilizando uma ferramenta alternativa, que visa a uma experiência educacional coletiva, fora da sala de aula.

Como ponto negativo, temos a dispersão por conta de inúmeras distrações online, como outras redes sociais, jogos, lembretes e notificações diversas. Então, estar focado é um novo desafio para educandos e educadores.

A aprendizado online requer, por parte de docentes e alunos, comprometimento, que vai além de somente diversão e da forma lúdica. Há inúmeras tarefas, horários a cumprir, pesquisas e outros novos afazeres nesse ensino autônomo.

Há também que se ter a ciência de que as redes sociais, de um modo geral, recebem e passam informações em tempo real. Logo, o feedback deve ser recebido e respondido de forma imediata.

Esse ainda é um caminho que estamos começando a percorrer, em que as possibilidades são infinitas e a complexidade também; portanto, a inserção das redes sociais no cotidiano escolar como uma nova forma de ensino e aprendizagem ainda é um desafio que precisamos aceitar, pois o ensino online nos aponta caminhos nunca antes utilizados. 


\section{REFERÊNCIAS}

A CHEGADA DA FAMÍLIA REAL NO BRASIL Grupo fechado - Plataforma facebook. Disponível em : https://www.facebook.com/groups/261791047827367/ Acesso em: 20 fev. 2019.

AGENCIA DE NOTICIAS IBGE - Nove entre dez usuários de Internet no país utilizam aplicativos de mensagens. Disponível em https://agenciadenoticias.ibge. gov.br/agencia-noticias/2012-agencia-de-noticias/noticias/20077-nove-entre-dezusuarios-de-internet-no-pais-utilizam-aplicativos-de-mensagens Acesso em: 20 fev. 2019.

ALARCÃO, I. Professores reflexivos em uma escola reflexiva. São Paulo: Cortez, 2003, p.31.

CBSI . 62 milhões de pessoas foram vítimas de crimes virtuais no Brasil em 2017. Disponível em: https://www.cbsi.net.br/2018/02/62-milhoes-de-pessoas-foram-vitimasde.html Acesso em: 19 mar. 2019.

FREIRE, P. Pedagogia da autonomia: saberes necessários à prática educativa. 50 . ed. Rio de Janeiro: Paz e Terra, 2000. p. 46

LEMOS, Cristina. Inovação na era do conhecimento. In: LASTRES, Helena M. M;. ALBAGLI, Sarita . (Org.). Informação e globalização na era do conhecimento. Rio de Janeiro: Campus, 1999. p. 122-144.

OBSERVATÓRIO DA IMPRENSA. O hipertexto como ferramenta no processo ensino-aprendizagem. Disponível em: http://observatoriodaimprensa.com. br/e-noticias/o-hipertexto-como-ferramenta-no-processo-ensino-aprendizagem/ Acesso em: 01 abr. 2019.

OFICINA DA NET. Ranking das maiores redes sociais. Disponível em: https://www. oficinadanet.com.br/post/16064-quais-sao-as-dez-maiores-redes-sociais. Acesso em: 16 fev. 2019.

SILVA, M. Sala de aula interativa. Rio de Janeiro: Quartet, 2000, p. 15. 